\title{
Mehmet Çilek, İmam Müslim ve Kitâbü't-Temyîz Adlı Eseri, Ankara: Fecr Yayınları 2017. 164 sayfa.
}

\section{Muhammet İkbal ASLAN*}

Mehmet Çilek'in İmam Müslim ve Kitâbǜt-Temyîz Adlı Eseri ismini taşıyan çalışması, hadis sahasında daha çok Sahîh'i ile gündeme gelen Müslim’in illet sahasında kaleme aldığ 1 et-Temyîz' ini konu edinir. Son yıllarda ülkemizde illet sahasında bazı çalışmalar yapılsa da bunlar hala istenilen seviyeye ulaşmamıştır. Çilek'in bu eseri ise et-Temyîz gibi önemli bir kitabı konu edinmesi bakımından önemlidir. Zira et-Temyîz oldukça erken bir dönemde kaleme alınan, hadis münekkitlerinin hadis tenkit yöntemini ortaya koyan ender eserlerden biridir. Çilek'in bu önemli eseri incelerken ne derece tutarlı ve başarılı olduğu ise bu yazıda ele alınacaktır. Aynı adla hazırlanmış bir yüksek lisans tezinin neşri olan eser iki ana bölümden oluşur. Birinci bölümde yazar Müslim’in hayatı ve eserlerine kısaca temas edip et-Temyîz in nüsha ve neşirlerini tanıtır. Ardından eserin Müslim’e aidiyetini inceleyip kitabı Müslim’den nakleden Mekkî b. Abdân hakkında bilgi vererek bölümü sonlandırır (s. 1541). Eserin ikinci bölümünde ise ilk olarak et-Temyîz'de yer alan hadis 1stılahlarına değinir. Bunun ardından "hacim bakımından elverişli olduğu" gerekçesiyle et-Temyîz'deki rivayetleri tek tek inceler (s. 43-149).

Eserin muhteva tahliline geçmeden önce Çilek'in kaynak kullanımındaki bazı sorunlara değinilmelidir. Çilek, eserin girişinde araştırmada herhangi bir kaynak sınırlamasına gitmediğini fakat bununla birlikte Türkçe kaynaklara çok fazla yer vermediğini, bunun yerine İslâmî ilimlerin muhtelif alanlarında "masâdır-1 asliyye" kabul edilen klasik kaynakları referans olarak kullandığını söyler (s. 12). Ancak kaynak sınırlamasına gidilmediği söylendikten sonra Türkçe kaynaklara yer verilmediğini söylemek bir çelişkidir. Ayrıca akademik bir tezde Türkçe eserlere başvurulmadığını söylemenin herhangi bir makul izahı yoktur. Ancak Çilek yalnızca Türkçe akademik tezleri değil Arap dünyasında Müslim ve illetle ilgili çalışmaların büyük bir kısmını da görmemiş ya da görmezden gelmiştir. Çilek’in "masâdır-ı asliyye" ifadesiyle neyi kastettiği de net değildir. $\mathrm{O}$, eserin girişinde temel hadis eserleri, şerh, tahrîc, zevâid, etrâf, tabâkât, fikıh, usûl vb. konularda "masâdır-1 asliyye" kabul edilen kaynakları kullanacağını söylese de örneğin bir fikıh ya da usûl kitabının böyle bir çalışmada neden "aslî kaynaklar" içerisinde bulunduğu izaha muhtaçtır. Söz konusu "masâdır-1 asliyye" kavramı eserde bir yerde daha geçer. Müslim’in et-Temyîz'de yer verdiği hadislerin birinin tahrîcini yaparken Çilek, ilgili hadisi "masâdır-ı asliyye"de bulamadığını söyleyip tâli sayılabilecek

Arş. Gör., İstanbul Ünivesitesi İlahiyat Fakültesi Hadis Anabilim Dalı, ikbal.aslan@istanbul.edu.tr Orcid no: 0000-0002-0645-6645 
kaynaklarda geçtiğini belirtir ve Dârekutnînin el-ïlelü'l-vâride’si ve diğer bazı kaynaklara atıf yapar (s. 68). Burada da Çilek'in "aslî" ve "tâlı̂" ile ne kastettiği belli değildir. Ayrıca ilel literatürünün en önemli eserlerinden olan İlelü’l-vâride’nin tâli bir kaynak olarak zikredilmesine mukabil bir hadis tezinde fikıh ve usûl alanlarındaki eserlerin "aslî" olarak nitelenmesi ilginçtir. Kaynak kullanımıyla ilgili söylenmesi gereken bir diğer husus yazarın yer yer birincil kaynaklara da başvurmamasıdır. Örneğin o, Zehebînin bir ifadesini İsmail Hakkı Ünal'dan (s. 132), Beyhakînin yer verdiği bir hadisi (s. 133) ve Ebû Zür'a’nın ifadelerini Bekir Tatlı'dan (s. 134) nakletmiştir.

Eserin $e t$-Temyîz'in genel hatlarıyla tanıtımını hedefleyen ve Müslim'in hayatı, eserleri, et-Temyîz' in nüshası, neşirleri, Müslim’e aidiyeti ve Mekkî b. Abdân hakkında kısa bilgiler veren birinci bölümde yazar, eseri neşreden muhakkiklerin verdiği bilgiler üzerine hemen hemen hiçbir şey eklemez. Nitekim bu durum yazar tarafından da dile getirilmiş, Abdülkâdir Mustafa el-Muhammedî ve Ahmed b. Mustafa Şaban neşirlerinin dirâse ve dipnot kısımlarından oldukça yararlanıldığı, bu iki nüshanın çalışmanın "en temel kaynaklarından" olduğu söylenmiştir (s. 12-3). Bu tutum da oldukça problemlidir. Zira her ne kadar nâşirlerin bilgileri yer yer aydınlatıcı ve diğer kaynaklara ulaşmada kolaylık sağlayıcı olsa da bir akademik tezde incelenen kitabın muhakkiklerinin dipnotlarını aslî kaynak görmek doğru değildir. Ayrıca Çilek'in nâş̧ir bilgilerine bu denli güvenmesi bazı hususları gözden kaçırmasına sebep olmuştur. Nitekim Çilek, eseri genel olarak tanıttığı bu bölümde, nüshanın tam haliyle günümüze gelmediğini belirtse de nüshanın tarihî serüveni, tam halinin hangi yüzyıla kadar ulaşabildiği hususunda hiçbir çaba sarf etmez. Yine onun verdiği bilgiler okuyucuya nüshanın tam bir tasvirini yansıtmaktan uzaktır. Örneğin Çilek, nüshada ihtisâr ve düşmelerin bulunduğunu söyler, ancak bunların mahiyetinden bahsetmez, bu sebeple okuyucunun zihninde nüsha hakkında bütünsel bir fikir doğmamaktadır.

Eserin ikinci bölümü ise daha problemlidir. Öncelikle, Çilek, gerek eserinin girişinde gerekse eser içerisinde çalışmasının asıl amacının "Müslim’in problemli rivayetleri değerlendirmesi ve bu değerlendirme esnasında uygulanan yöntemin ortaya konulması" (s. 11) olduğunu vurgular. Yazar bir başka yerde de et-Temyîz in hacim bakımından elverişli olması sebebiyle eserin muhtevasını değerlendirmenin en iyi yolunun eserde yer alan illetli her bir rivayetin teker teker incelenmesi olduğunu belirtir (s. 46). Hâlbuki yazardan beklenen Müslim’in aynı yöntemi (muâraza) uygulayarak tenkit ettiği her bir rivayeti teker teker incelemek değil, bu rivayetlerin incelemesinde Müslim’in takip ettiği yöntem hakkında bütüncül bir fikir vermekti. Bu haliyle Çilek'in çalışmasının Müslim'in et-Temyîz'deki yöntemini ortaya koyduğu söylenemez. Zira yazarın, Müslim’in yöntemiyle ilgili ortaya koyduğu yargılar oldukça kısıtlıdır. Bunların tamamında da Müslim’in eserde hadisleri birbirleriyle karşılaştırarak hadisler hakkında hüküm verdiğinden öte bir şey demez. Örneğin yazar ikinci bölümün girişinde (s. 47) Müslim’in yöntemiyle ilgili şöyle der: 
"Müslim bu eserde karşılaştırmalı bir yöntem takip etmiş, rivayetleri mukayese ederek çeşitli sonuçlara ulaşmıştır. Hadis usûlünde şaz-mahfuz, mảruf-münker karşılaştırılması yapılarak sahih ile zayıf birbirinden ayrılıyor ve buna göre hadis hakkında hüküm veriliyorsa, Müslim'in de Kitâbü't-Temyîz'deki usûlü illetli rivayetler ile diğerlerinin karşılaştırılmasıyla bir neticeye ulaşmak olmuştur."

Bu ifadeler birçok açıdan problemlidir. İlk olarak yazarın hadis usûlü eserleriyle ilgili ifadeleri oldukça ilginçtir. Yazar, hadis usûlünde şẫz-mahfûz, ma'rûf-münker ayrımı yapıldığını söyler ki bu doğrudur. Fakat sonrasındaki ifadelerinde, yani hadis usûlü eserlerinde bu ayrım ve karşılaştırma yapıldıktan sonra sahih ile zayıfın birbirinden ayrıldığını belirtmesi isabetli değildir. Çünkü bu eserler sahih ve zayıf hadislerin tespit edilip ayrıştırıldığı kaynaklar değil, teorik yönü ağır basan ve râvi, rivayet ve rivayetin aktarımında aranan şartları tartışmayı ve bunlar hakkında genel bilgiler vermeyi hedefleyen kitaplardır. Yazarın yukarıdaki ifadelerinden sonraki cümle de problemlidir. Zira o eserde "Sahih haberlere muhalefet", "İcmâya, hafızların ya da çoğunluğun rivayetine muhalefet"in eserde kullanılan mukayese/mukabele yöntemlerine örnek olarak verilebileceğini söyler (s. 47-8). Yazarın "icmâya muhalefet"ten neyi kastettiği açık değildir. O, et-Temyîz'de metni hatalı bulunan rivayetler içerisinde aynı başlı̆̆ı kullanmıştır. Müslim’in "Âlimlerin Hilâfına İttifak Ettikleri, Hz. Peygamber'den Nakledilmiş Bir Âdıdı (Destekleyicisi) Olmayan Fâsit Bir Rivayet” başlığını kullandığını söyleyip illetli rivayeti nakleder. Çilek'in eserde kullanılan mukayese yöntemlerinden "İcmâya muhalefet" şeklindeki bir başlı̆̆ zikretmesinin sebebi Müslim’in "Âlimlerin hilafına ittifak ettikleri..." ifadesi olsa gerektir. Çilek muhtemelen Müslim’in bir fikıhçı olarak hareket ettiğini, âlimlerin tamamının aksine görüş bildirdiği için hadisi illetli saydığını düşünmüştür. Hâlbuki kendisi de Müslim’in bu hadisi Hz. Peygamber, sahâbe, tabiûn ve onlardan sonraki âlimlerden nakledilen haberlere muhalif olması sebebiyle tenkit ettiğini belirtir (s. 111). Yani Müslim'in hadisi tenkit etmesinin sebebi hadisin Hz. Peygamber'den sahih rivayetlerle çelişmesidir. Dolayısıyla "icmâya muhalefet" olarak isimlendirilen yöntemle "sahih haberlere muhalefet" arasında fark yoktur. Çilek'in zikrettiği diğer yöntem için de aynı durum söz konusudur. Zira "sahih haberlere muhalefet" ile "hafızların rivayetine muhalefet" arasında da herhangi bir fark olmayıp ikisi aynı şeydir. Çilek’in zikrettiği "çoğunluğa muhalefet" ise muhtemelen yanlış anlaşılmıştır. Zira eseri inceleyen herkesin rahatlıkla görebileceği gibi Müslim’in "çoğunluk" ile kastettiği hafız râviler ve onların rivayetleridir. Dolayısıyla bu mukabele yöntemlerinin hepsi aslında aynıdır.

Çilek, eserinde Müslim’in rivayetleri birbirleriyle karşılaştırarak hadisler hakkında hüküm verdiğini tespit edebilmişse de bu yöntem hakkında hiçbir şey söylemez. Hâlbuki yazar, en azından eseri neşreden M. Mustafa el-A‘zamînin et-Temyîz'e giriş mahiyetinde kaleme aldığı Menhecü̉n-nakd inde’l-muhaddisîn adlı esere baksaydı bu yöntemin ne olduğu, kimler tarafından ve ne zaman kullanıldığı hakkında bilgi edinebilirdi. Özellikle modern çalışmalarda "muâraza" olarak isimlendirilen ve erken dönem hadis münekkitlerinin tamamı tarafından kullanılan bu yöntem hakkında Çilek suskundur. Hâlbuki muâraza yöntemini 
oldukça açı bir şekilde yansıtan en önemli eser et-Temyîz'dir. Müslim'in et-Temyîz'deki yöntemini ortaya koyma iddiasındaki bir çalışmada böyle bir eksikliğin bulunması ciddi bir hatadır. Muhtemelen Çilek, eserin tamamını kuşatan bir bakış açısından ziyade Müslim’in aynı yöntemi uygulayarak tenkit ettiği her bir rivayeti parçacı bir biçimde incelediği için böyle bir hataya düşmüștür.

Çilek, İkinci Bölümü et-Temyîz'de yer alan rivayetleri "İsnâdında Problem Bulunan", "Metninde Problem Bulunan" ve "İsnâd ve Metninde Problem Bulunan" rivayetler olmak üzere üç ana başlığa ayırmıştır ki bu kanaatimizce isabetlidir. Fakat yazarın buradan sonraki alt başlıkları oldukça problemlidir. Örneğin o, isnâdında hata bulunan rivayetleri "Galat", "Vehim", "Münker" ve "Hata" olmak üzere dört alt başlı̆̆a ayırmıştır. İlk bakışta Müslim’in bu dördünü birbirinden farklı değerlendirdiği düşünülebilirse de durum böyle değildir. Zira Müslim, eserde bu dört kelimeyi aynı anlamda kullanır. Nitekim bu husus bizzat yazar tarafından da söylenir (s. 104; s. 123). Fakat buna rağmen yazar başlıkları niçin böyle isimlendirdiğini belirtmez. Bu durum Çilek'in eserinde bir kavram karmaşasına sebep olmuştur. Kavramlarla ilgili bu karışıklık eser boyunca sürer. Öncelikle Çilek, bir ilel türü eseri incelemesine rağmen illetin tanımılla ilgili "hadiste bulunan ve hadisin sıhhatine zarar veren gizli sebep” ifadelerini Mücteba Uğur'dan nakleder. Anlaşıldığı kadarıyla yazar illetle ilgili modern çalışmaları "masâdır-1 asliyye"kapsamında görmektedir. Fakat yazar en azından İbnü’s-Salâh’nki gibi klasik hadis usûlü eserlerinin illet bahislerini inceleseydi bu tanımın mütekaddim dönem için geçerli olmadığını görürdü.

Çilek İkinci Bölümde "Eserde Kullanılan Hadis Istılahları" başlığı altında et-Temyîz'de yer alan hadis kavramlarını tespit etmeye çalışır. Bu başlık altında, herhangi bir pratik faydası olmamasına rağmen eserde yer alan ve "hadis usûlü, cerh ve tadîl ıstılahları kapsamında değerlendirilebilecek pek çok kavramı [?]" alt alta dizer. Ancak buradaki "Ehlü'l-Kufe" (s. 50), "fesede'l-hadîs" (s. 50), "istenkera" (s. 51), "Kûfiyyûn" (s. 51), "lem yesma" (s. 51), "elmuhti”" (s. 51), "Rivâyetü'l-Basriyyîn" (s. 52), "Rivâyetü'l-Kûfiyyîn" (s. 52) ve "Temyîz" (s. 53) gibi ifadelerin bir hadis ıstılahı olmayıp kelime anlamında kullanıldığı açıktır. Kavramlarla ilgili karmaşa bunlarla sınırlı değildir. Yazar yer yer aynı kelimelerin farklı kavramları ifade ettiğini de söyler ve bu çerçevede metni hatalı bulunan rivayetler içerisinde "Münker" alt başlığına yer verip Müslim’in aslında "münker" lafzını kullanmadığını, fakat onun "müstenker" lafzıyla münkeri kastettiğini belirtir (s. 117). Halbuki yazar daha önce et-Temyîz'de yer alan bir rivayette Müslim’in "müstenker" dediği kısmı "Müslim bu durumun makul olmadığını (müstenker) ve .... söylemektedir” (s. 105) şeklinde açılamıştır. Dolayısıyla yazar eserinde, bir yerde aslında Müslim'in bu ifadeyi kelime anlamında kullanıldığının farkındayken aynı kelimeyi bir başka yerde "münker" terimiyle ifade etmektedir. Yine yazar Müslim’in eserde sıkça geçen "gayr-1 mahfuz" ifadesini genellikle "şâz" anlamında (s. 57; s. 103; s. 113), bir yerde ise "münker" anlamında kullandığını söyler (s. 69). Aslında kelimenin nasıl kullanıldığı oldukça açıktır. Müslim "gayr-1 mahfuz" ifadesini kelime anlamında kullanmış, yani bu ifadeyle bilinen ve yaygın olan hadislere muhalif rivayeti kast etmiştir. Fakat yazar 
anakronik bir hataya düşerek Müslim'in bu ifadeyle sonradan yerleşmiş kavramlardan hangisini kastettiğini tam olarak belirleyememiş ve yine bir kavram karmaşasına sebep olmuştur. Eserdeki anakronik hatalar bunlarla da sınırlı değildir. Örneğin yazar, Müslim’in bir rivayetteki ifadeleriyle ilgili ciddi bir yanlışa düşmüştür. Müslim, namazda Hz. Peygamber'in Fâtiha sûresinden sonra "âmîn" lafzını gizli olarak okuduğunu ifade eden Şu'be rivayetini tenkit eder. Konuyla ilgili doğru kabul ettiği rivayetleri naklettikten sonra da "Kad tevâterat er-rivâyâtü küllühâ enne’n-nebiyye cehera bi âmîn” der (Müslim, et-Temyîz [nşr. Muhammedî], s. 108). Çilek, Müslim'in ifadelerinde geçen "tevâtera" ifadesini yanlı̧ anlayarak "Müslim, Hz. Peygamber'in açıktan, sesli bir şekilde âmin dediğine dair rivayetlerin 'tevâtür' derecesinde olduğunu, Vâil'den rivayet edilen hadisin buna delalet ettiğini söylemektedir" demiştir (s. 76). Hâlbuki bilindiği gibi erken dönem hadis âlimleri, "tevâtür" lafzını yer yer kullansalar da bununla Hatîb el-Bağdâdî ve sonrasında İbn Hacer'le hadis usûlünde yer edinen terim anlamındaki tevâtürü değil, rivayetlerin yaygın ve birbirlerini destekleyici mahiyette nakledilmesini kastetmişlerdir.

Yazarın et-Temyîżi değerlendirmesindeki önemli bir diğer hatası da eserin yazım sebebini yanlış olarak tespit etmesidir. Yazar, bir kişinin Müslim’den hata etmeleri sebebiyle rivayetleri hadis âlimlerince hatalı kabul edilen râvilerin hadislerini zikretmesini istediğini Müslim’in de bu konuda açılamalarda bulunacağını söylediğini belirtmiştir. Bu ifadelerinin ardından yazar "Müslim'in ifadelerinden anlaşıldığına göre "râvilerden kaynaklanan ve hata bulunan rivayetlerin açlklanması" eserin telif sebebini teşkil etmektedir" der (s. 46-7). Hâlbuki eser, dikkatlice incelendiğinde et-Temyîz'in yazlma sebebinin Çilek'in bahsettiği gibi olmadığg rahatlıkla görülür. Nitekim Müslim’in ifadeleri (et-Temyizz, s. 83-4; s. 191) bir bütün olarak incelendiğinde onun bu kitabı yalnızca illetli rivayetler hakkında bilgi vermek için yazmadığı anlaşılacaktır. Bilakis müellif bu eseri, hadis ve râvi tenkidini anlamayıp öğrenmek isteyenler ve hadis tenkidine karşı çıkanlara bir cevap teşkil etmesi için kaleme almıştır. $\mathrm{Bu}$ durum eserde incelenen hadislerin diğer ilel türü kitaplarına nispetle daha az ve fakat detaylı olarak ele alınmasından da anlaşılır. Bunun yanında müellif, eserde aynı zamanda hadislerin nasıl tenkit edileceğine dair yöntemler de zikreder (s. 85-6; s. 90). Tüm bunlar eserin yazım amacının Çilek'in zikrettiği gibi olmadığını gösterir.

Müslim'in Sahîh'i üzerine yapılmış modern çalışmaları incelememiş olması yazarı kritik hatalara düşürmüştür. Çilek, eserinde yalnızca Müslim üzerine yapılmış iki çalışmaya atıf yapar. Bunların ilki Âşur Dihnînin Menhecü̉l-İmâm Müslim b. el-Haccâc fî zikri'l-ahbâri'l-muallele min hilâli Kitâbihî el-Müsnedü's-Sahîh, diğeri ise Muhammed Tavâlibe'nin elİmâm Müslim ve mehecühû fî Sahîhî adlı eserleridir. Ancak Çilek, bu iki esere de yalnızca birkaç yerde atıf yapar. Hâlbuki yazarın Müslim’le ilgili görüp incelediği çalışmaları yeterli bir şekilde kullanması, gözden kaçırdığı önemli çalışmaları da incelemesi beklenirdi. Örneğin o, Melîbârî̉nin Abkariyyetü'l-İmâm Müslim'ini, Rebî' b. Hâdî el-Medhalînin Menhecü'l-İmâm Müslim fì tertibi Kitâbihî es-Sahîh'ini, Muhammed Avvâme’nin Hazfu tarafin mine’l-hadîs ile birlikte basılan Min menheci'l-İmâm Müslim adlı eserlerini kullanmaz. Bu durum et-Temyîz 
ve Sahîh'te ortak olarak zikredilen hususlarda yazarın hata etmesine sebep olmaktadır. Nitekim o, Müslim'in et-Temyîz'de eleştirdiği Saîd b. Ubeyd'in kasâme ile ilgili hadisini Sahîh'te zikretmesini bir çelişki olarak görür (s. 94). Hâlbuki yazar en azından Sahîh'in "Mukaddime"sini ya da kitabının içerisinde atıf yaptığı Dihnînin (Menhecü'l-İmâm Müslim, s. 160) ve kitapta hiç değinmediği Melîbârînin (Abkariyyetü’l-İmâm Müslim, s. 18-9) mezkûr eserlerini inceleseydi daha tutarlı bir yargiya varabilirdi.

Burada işaret edilmesi gereken bir diğer husus Çilek'in Müslim’in Sahîh'inin "Mukaddime"sini de eserinde hiç kullanmamasıdır. Hâlbuki et-Temyı̂z'de işlenen birçok hususa Müslim "Mukaddime"de değinmiştir. Bu durum Müslim’in anlaşılamamasına sebep olmuştur. Örneğin yazar Müslim’in ziyâdetü’s-sika ile ilgili görüşlerini tam olarak anlayamamıştır. Müslim, Cibrîl hadisi olarak bilinen rivayetin bir tarikini eleştirir. Müslim'in eleştirdiği rivayete göre bu hadis "İbn Ömer $\rightarrow$ Hz. Peygamber" isnâdıyla nakledilir. Müslim bunu Kûfeli râvilerin rivayet ettiğini, Basralıların ise "İbn Ömer $\rightarrow$ Ömer $\rightarrow \mathrm{Hz}$. Peygamber" şeklinde naklettiğini belirtir, hâfız olup hadiste ziyâde yapanın hadisinin kabul edileceğini, çünkü hadis nakletmenin, arkadaşının hatırlamadığı bir hususta şâhitlik yapmaya benzediğini söyler (et-Temyîz, s. 155). Çilek, Müslim’in bu ifadelerini “tuhaf bir kıyas” olarak niteleyip İbn Receb’in de Müslim’i bu konuda eleștirdiğini belirtir (s. 130). Ancak Müslim’in hem et-Temyîz'deki (et-Temyîz, s. 128) hem de "Mukaddime"deki (Müslim, Mukaddime [nşr. Fuâd Abdülbâkî], I, 7) görüşleri beraber düşünüldüğünde onun ziyâdetü’s-sika ile ilgili görüşlerinde bir tuhaflı̆̆ın bulunmadığı görülecektir. Buna göre Müslim, ziyâdetü’s-sikayı mutlak olarak değil yalnızca hâfızası sağlam, diğer râvilerin rivayetlerine oldukça az muhalefet eden râvilerden kabul etmektedir. Nitekim Çilek'in atıf yaptığ İ̉bn Receb de bu ifadeyi garipsemiş ve fakat ardından bunun Müslim’in ve diğer hadis imâmlarının görüşü olmadığını, Müslim’in Cibrîl hadisindeki ziyâdeyi kabul etmesinin sebebinin Basralı râvilerin bu hadisi Kûfelilerden daha iyi ezberlemesi olduğunu belirtmiştir (Şerhu İleli't-Tirmizî [nşr. Hemmâm Abdurrahîm Saîd], II, 643). Ancak Çilek, burada hem et-Temyîz'deki diğer ifadeleri hem de Müslim’in "Mukkadime"sindeki görüşleri dikkate almamıştır. Yine de yazar, İbn Receb’in ifadelerini nâş̧irin girişinden değil de kitabın ana kısmından okusaydı bu yanlışa düşmezdi. Nitekim Çilek, İbn Receb’in ifadelerini nâş̧irin girişinden nakletmiştir (s. 130). Nâş̧ir ise girişinde hadisteki ziyadenin niçin kabul edildiğine dair İbn Receb’in ifadelerini aktarmamış (Şerh, I, 217 [nâş̧irin girişi]), bu durum da muhtemelen Çilek'i hataya düşürmüştür.

Çilek'in metninde önemli tercüme hataları da mevcuttur. Örneğin isnâdı hatalı rivayetler içerisinde incelenen İbn Ömer hadisinde ciddi bir hata söz konusudur. Müslim "Mücâhid $\rightarrow$ İbn Ömer" isnâdıyla nakledilen İbn Ömer’in "Hz. Peygamber’in akşam namazından sonra ve sabah namazında önce kıldığı [sünnet olan] iki rekâtta Kâfirûn ve İhlâs sûrelerini okuduğunu 20 defadan fazla işittim" hadisini tenkit eder. O, bu rivayetin "İbn Ömer $\rightarrow$ Hafsa" şeklinde olması gerektiğini, İbn Ömer’in bunu Hafsadan naklettiğini söyler (et-Temyîz, s. 173-6). Hadisi değerlendirirken Müslim “ve hâza’l-haber vehemün an İbn Ömer" ifadelerini kullanır. Çilek bu ifadeyi yanlış anlayıp hadiste hata yapan râvi hakkında "Müslim’in bu 
râvi ile İbn Ömer'i kastettiği ve vehim ile galat kavramlarını aynı anlamda kullandığı anlaşılmaktadır” demiştir (s. 55). Hâlbuki ifadede de açıkça görüldüğü üzere Müslim, İbn Ömer’in hata ettiğini söylemez, "Bu rivayetin İbn Ömer'den nakledilmesi hatadır" der. Zaten Müslim bu cümleden sonra hadisi İbn Ömer'den doğru nakleden kimselerin hadislerini zikredeceğini söyleyip bu rivayetleri nakleder. Dolayısıyla Müslim’in yukarıdaki mezkûr ifadeleri ile İbn Ömer'i kastetmediği açıktır. Tercüme hatalarının bir diğer örneği ise Müslim’in Zührî̉en nakledilen hadisle ilgili değerlendirmesindedir. Hz. Âişe’nin naklettiğine göre Hz. Âişe ve Hafsa'ya oruçlu oldukları bir gün yemek ikram edilir. Onlar da oruçlarını bozup yemeği yerler. Bu durumu sorduklarında Hz. Peygamber bozdukları güne karşlık bir gün oruç tutmalarını emreder. Müslim hadisi "İbn Şihâb $\rightarrow$ Urve" isnâdıyla nakleden râvilerin rivayetlerini eleştirir. Zira onun aktardığına göre hadisi İbn Cüreyc de nakletmiş ve Zührîye bu hadisi Urve'den alıp almadığını sormuş, o da hadisi Urve'den nakletmediğini, Süleyman b. Abdülmelik hilafetinde Hz. Âişe’ye soran bazı kimselerden işittiğini söyler (et-Temyîz, s. 193). Müslim hatalı rivayetleri naklettikten sonra "Zümeyl Mevlâ İbn Urve $\rightarrow$ Urve" isnâdını Zümeyl'in mechûl olması sebebiyle zayıf kabul eder. Ardından "Cerîr b. Hâzim $\rightarrow$ Yahya b. Saîd $\rightarrow$ Amra $\rightarrow$ Âişe” isnâdını nakleder. Yahyảnın hadisini müsned olarak sadece Cerîr b. Hâzim'in naklettiğini, Cerîr'in ise Yahyadan hadis nakletmekle meşhur olmadığını, ondan sadece az sayıda hadis aldığını ifade edip bu rivayetlerin de neredeyse hepsinin hatalı olduğunu belirtir (ve lâ yekâdu ye’tî ala't-takvîm ve'l-istikâme) (et-Temyîz, s. 194). Ancak Çilek, yukarıda parantez içerisinde verilen ifadeyi yanlış anlayıp "Neredeyse bu rivayeti de doğru şekilde nakledemeyecekti” șeklinde tercüme etmiş ve bunun sonucunda onun bu isnâdla gelen hadisi sahih kabul ettiği sonucunu çıarmıştır (s. 73). Hâlbuki Müslim’in ne kastettiği oldukça açık olup ifadenin doğru tercümesi yukarıda verilmiştir.

Çilek'in eseriyle ilgili değinilmesi gereken son husus eserin yeterli bir yayına hazırlık aşamasından geçmemiş olduğudur. Zira eserde birçok düşük cümleler yer aldığı gibi s. 40’taki "Kitâbü’t-Temyîz'den isim olarak bahsetme..." şeklindeki paragrafta olduğu gibi yazarın kastının anlaşılamadığı yerler de vardır. Özellikle paragrafın sonuna doğru yazarın ne kastettiğini anlamak oldukça zor olmaktadır. Yazarın s. 93-4’teki “Herşeyden önce Müslim...” şeklinde başlayan cümlesiyle neyi kastettiğini de anlamak güçtür.

Tüm bu hususlara rağmen Müslim’in et-Temyîz'i gibi önemli bir eserin Türkiye’de bir akademik çalışmaya konu olması sevindiricidir. 